\title{
The difference in def-t and DMF-T index between autistic and normal children
}

\author{
Prima Abigail Gayatri*, Yetty Herdiyati*, Eka Chemiawan* \\ Department of Pedodontics, Faculty of Dentistry, Universitas Padjadjaran.
}

\begin{abstract}
Introduction: One of the problems in the development of a child is autism. Children with autism have limitations in social interaction and communication. There are differences in parenting and food consumption between normal and autistic children that may lead to differences in caries activity. The research was conducted in order to obtain the difference of index def-t and DMF-T between children with autism and normal children. Methods: This study was performed as a cross-sectional analytical research, using equality of two proportions and Mann-Whitney to analyze the differences of index def-t and DMF-T index children with autism and normal children. The research sample consisted of 23 children with autism of Yayasan Our Dream, Yayasan Pelita Hafizh and SLB Prananda and 23 normal children of MI Cikapayang. Results: The results of this research showed that the index def-t of children with autism was 1.21 and normal children was 3.69. The DMF-T index of children with autism was 1.56 , while the normal children was 2.26. Conclusion: The conclusion of this research was that there was no significant difference in def-t index in children with autism and normal children except for the "e" (indicated for extraction) and there was a significant difference in DMF-T index between children with autism and normal children.
\end{abstract}

Keywords: def-t and DMF-T index, children with autism and normal children

\section{INTRODUCTION}

Children with autism have problems interacting with the social environment and communicating, so they need to get special care about their dental and oral care from an early age by parents. ${ }^{1}$ Parents have a major influence on the health of a child. Maintenance of dental and oral health of children become factors that need to be considered parents from early, especially in children with autism.

Motor and communication disability in children with autism leads to a perception that autistic children have poor dental and oral health compared to normal children. Behavior of autism complicates routine maintenance and control of dental and oral hygiene. Children with autism tend to have weak masticatory muscles and are less able to coordinate, hence the tendency to salivate. They prefer sweet foods and are less able to coordinate the tongue and chewing muscles, causing them to keep food in their mouths instead of chewing. The habit of consuming sweet foods and their behavior is what causes autistic individuals susceptible to caries. ${ }^{2}$ A study in Turkey and Surabaya denied the statement. The study proved that children with autism had a lower caries prevalence compared with normal children at 
an early age because of the constraint on the consumption of sugary foods. The dietary regulation in children with autism has been done early and dental and oral hygiene measures are monitored directly by caregivers or parents. ${ }^{1}$ In contrast to autistic children, parents often do not pay attention to food consumption so normal children are prone to consume cariogenic foods and the lack of good dental and oral control are one of the factors that can trigger the occurrence of caries in normal children. The purpose of the study was to obtain data and to see the difference of def-t index and DMF-T among autistic children with normal children in some educational institutions such as Our Dream Foundation, Pelita Hafizh Foundation, Prananda SLB, and MI Cikapayang Bandung.

\section{METHODS}

The research was a comparative analysis with cross-sectional study, with the aid of questionnaire. The subjects were 23 children with autism and 23 normal children aged $7-12$ years using random purposive sampling technique.

Variables in this study included caries, children with autism and normal children. Tools and materials required for this study included mouth mirror, explorer, tweezers, 70\% alcohol, cotton, water, cotton pellet, questionnaires and dental caries examination form. Questionnaires were given to normal children and parents of autistic children to investigate the influence on the difference between dental caries between children with autism and normal children. The caries examination was performed using the def-t formula (decay, indicated for extraction, filled, teeth) for primary teeth and DMF-T (Decay, Missing, Filled, Teeth) for permanent teeth.
The study was conducted in two visits. During the first visit the identity (name, type of age, and age), informed consents were given, and questionnaires were given to both normal children and the parents of autistic children. During the second visit, dental caries examination was carried out using the above formula and then recorded on the examination form.

\section{RESULTS}

The sample distribution based on school can be seen in table 1 and the sample distribution based on the age of the children can be seen in table 2 .

Table 1. Distribution of Frequency of Children Based on School

\begin{tabular}{cccc}
\hline No. & Institute & $\mathrm{f}$ & $\%$ \\
\hline 1 & Our Dream Foundation & 10 & 21.73 \\
2 & Pelita Hafizh Foundation & 7 & 15.21 \\
3 & SLB Prananda & 6 & 13.04 \\
4 & MI Cikapayang & 23 & 50 \\
\hline & Jumlah & 46 & 100 \\
\hline
\end{tabular}

Based on the table above, the majority of subjects were from MI Cikapayang with a number of 23 people (50\%), secondly, Our Dream Foundation Distribution Based On School

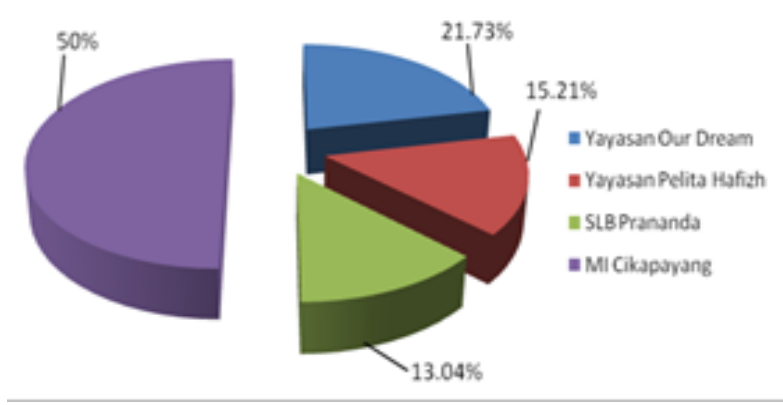

Figure 1. Distribution Based On School

Table 2. Distribution Based on Age

\begin{tabular}{ccccccccc}
\hline \multirow{2}{*}{ Age } & \multicolumn{2}{c}{ Our Dream } & \multicolumn{2}{c}{ Pelita Hafizh } & \multicolumn{2}{c}{ Prananda } & \multicolumn{2}{c}{ Ml Cikapayang } \\
\cline { 2 - 8 } & F & $\%$ & F & $\%$ & F & $\%$ & F & $\%$ \\
\hline 7 & 1 & 10 & 0 & 0 & 0 & 0 & 1 & 4.34 \\
8 & 2 & 20 & 0 & 0 & 2 & 33.33 & 4 & 17.39 \\
9 & 1 & 10 & 0 & 0 & 0 & 0 & 1 & 4.34 \\
10 & 1 & 10 & 2 & 28.57 & 2 & 33.33 & 5 & 21.7 \\
11 & 3 & 30 & 3 & 42.85 & 1 & 16.66 & 7 & 30.4 \\
\hline Total & 10 & 100 & 7 & 100 & 6 & 100 & 23 & 100 \\
\hline
\end{tabular}


with a number of 10 people (21.73\%), Pelita Hafizh Foundation with 7 subjects (13.04\%), and lastly, SLB Prananda with 6 subjects (13.04\%). More details can be seen in the following diagram.

The def-t index of autistic children at Our Dream Foundation, Pelita Hafizh and SLB Prananda Bandung was 1.21 and the def-t index of normal child in Ml Cikapayang was 3.69. According to WHO, the def-t index of autistic children fell in the low category of $1.2-2.6$, whereas the def-t

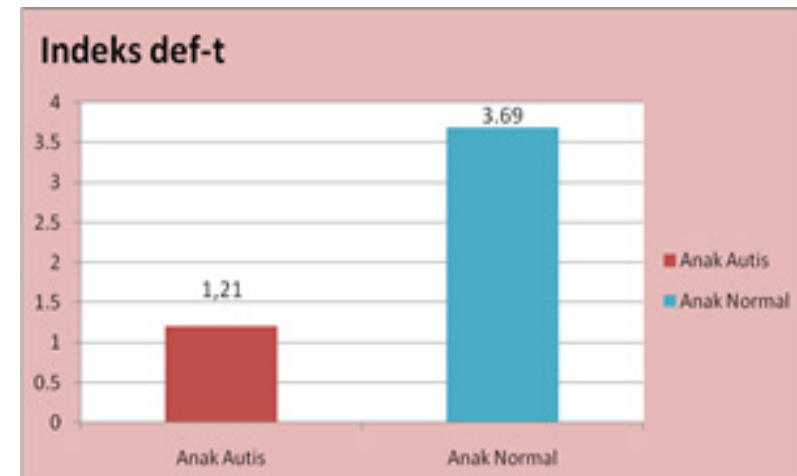

Figure 2 Comparison of def-t index between Autistic Children and Normal Children

index of normal children were included in the moderate category of $2,7-4,4$.

The results showed that the def-t index in normal children was higher than that of autistic children. The Mann Whitney statistical test was conducted to find out whether there is a significant difference between autistic children's deficit index (Our Dream Foundation, Hafizh Pelita and SLB Prananda) and normal child (MI Cikapayang) in Bandung.

The results showed no significant difference in the def-t index between autistic children and normal children except for index "e" which showed a very significant difference that is $\mathrm{P}=0,002$ (Ap-

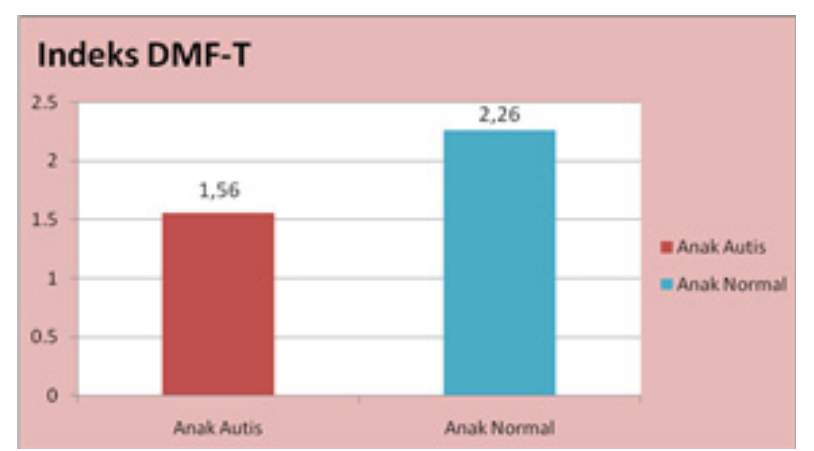

Figure 3. Comparison of DMF-T Index between Autistic Children and Normal Children pendix 17). The autistic children's DMF-T index at Our Dream Foundation, Pelita Hafizh and SLB Prananda Bandung is 1.56 and normal children in $\mathrm{Ml}$ Cikapayang is 2.26. According to WHO, the DMF-T index of children with autism and normal children is in the low category 1,2 - 2,6.

The results showed that the DMF-T index in normal children is higher than autistic children. The Mann Whitney statistical test was carried out to find out whether there was a significant difference between autistic children index and normal children. The results showed that there was a significant difference in the DMF-T index between autistic children and normal children, $\mathrm{P}=0.039$.

\section{DISCUSSION}

Based on the results obtained, the def-t index of autistic children was 1.21 while the the def-t index of normal children was 3.69. The results showed that the def-t index of normal children was higher than that of autistic children, but the statistical results showed no significant difference in the def-t index between autistic children and normal children except for "e" (indicated for extraction) that showed a very significant difference $(P=0.002)$. The DMF-T index of children with autism was 1.56 and the normal child was 2.26.

Based on the results of statistical analysis (Appendix 17), there was a significant difference in the DMF-T index between children with autism and normal children $(p=0.039)$. This might be a result from several factors, including the difference in the way of how parents maintain oral health in autistic children and normal children, dietary differences and the difference in oral hygiene measures.

In general, the oral health level of autistic children is lower than normal children. Children with autism have a high level of caries risk because of their inability to understand and use verbal language as a medium of communication hence the inablitiy to grasp and understand the various information provided by the environment. ${ }^{3}$ Increased caries risk in children with autism is related to their interest in sweet foods, the lack of masticatory muscle capacity. ${ }^{4}$

Based on the results of research conducted in several autism institutes and schools in the city of Bandung, it is known that there is no signifi- 
cant difference between the def-t index of children with autism and normal children. However, the value of DMF-T index in normal children was 2.26, which was greater than that of autistic children which was 1.56 . This is in accordance with the results of a survey conducted by researchers that the caregivers and parents of autistic children play a more active role in maintaining their oral health. 17 out of 23 respondents help in maintaining the health of their teeth and mouth by intervening directly such as brushing their child's teeth. $43 \%$ of respondents who have autistic children prepare special carbohydrate diet to avoid hyperactive behavior in their children. Gluten and casein are carbohydrates that children with autism should avoid.

This is because these two types of carbohydrates have a protein that is difficult to digest. Digestive enzymes in autistic children are very weak which can lead to indigestion. In addition, it can cause diarrhea and can affect the central nervous system which causes hyperactive behavior in autistic children. ${ }^{5}$ The minimum consumption of carbohydrates results in lower dental caries in children with autism. The organic acids produced from carbohydrate metabolism in plaque cause the $\mathrm{pH}$ to fall below normal and result in the demineralization process of caries. ${ }^{6}$ In children with autism, this demineralization process is minimal because of the limited consumption of carbohydrates.

A significant difference in the "e" value (teeth with indication of extraction) on the higher def-t index is shown in the def-t index of normal children. This is because of the frequency and consumption of sweet foods in normal children are often not limited by parents. In addition, 14 (60\%) of normal children had a preference for sweet foods. This condition if not accompanied by good dental maintenance, resulted in increased plaque accumulation on teeth that lead to dental caries.

In addition, higher carbohydrate consumption in normal children is also one of the factors that cause caries. Carbohydrates are bacterial substrates in plaque which can produce acid and undergo extracellular synthesis of polysaccharides. Glucose in carbohydrates aids in bacterial metabolism where lactic acid is formed and cause demineralization of tooth enamel.

One of the carbohydrates often found in food is sucrose, which plays the most important role in caries formation in comparison to other carbohydrate types. ${ }^{7}$ The knowledge of oral health maintenance in normal children is good referring to their habit of brushing teeth during shower and before bedtime. In contrast, children with autism mostly had their teeth brushed by their parents only during shower. It is most likely due to the tendency of autistic children who like performing actions / rituals routinely and their abnormal or hyperactive behavior, such as raging, screaming and hitting..$^{5,8}$

Children with autism are incapable of effective verbal and non-verbal communication, so it is difficult for them to express their desires. Autistic children prefer staying silent and shrugging off their parents' hands if they want something. They are difficult to talk to and are often not understood. Therefore, caregivers or parents often have difficulty teaching them how to maintain oral hygiene. Children with autism have a strict routine. $^{2}$

If dental and oral hygiene measures are not their regular routine, they will refuse to do it. Parents whose children are diagnosed with autism should treat their children with caution, including oral hygiene. They tend to take care of oral health and hygiene by intervening directly such as brushing their children's teeth and be selective in their children's food because dental care in children with autism can be difficult if there is caries. On the other hand, parents of normal children tend to be less alert and less attentive to their child's dental health. This is because of the assumption that primary teeth do not need to be treated as they will be replaced by permanent teeth. ${ }^{9}$

Significant differences in the DMF-T index between autistic children and normal children may be a result of the differences in tooth structure in primary teeth and permanent teeth. In deciduous tooth, the enamel layer and dentine are thinner and the pulp chamber is wider. On the contrary, permanent teeth have a thicker layer of enamel which is why deciduous teeth is more susceptible to caries compared to permanent teeth. ${ }^{10}$

According to the examination of def-t and DMFT values, the number of caries are higher in permanent teeth due to the lack of dental health maintenance. In addition, one of the factors related to the increase of caries in permanent teeth is 
the lack of parent supervision at school where the children can consume snacks uncontrollably.

\section{CONCLUSION}

Based on the results of research on the def-t index and DMF-T in autistic children from Our Dream Foundation, Pelita Hafizh Foundation, SLB Prananda Bandung and normal children in MI Cikapayang Bandung, it can be concluded that there is no significant difference in the def-t index between autistic children and normal children except for index "e" on def-t, while there is a difference in the DMF-T index between autistic children and normal children.

\section{REFERENCES}

1. Necmi N, Vehit HE, Koksal S. Do autistic children have higher levels of caries? A cross-sectional study in Turkish children. 2007;25(2):97-102.

2. McDonald, Ralph E., David R. Avery and Jeffrey A. Dean. Dentistry for the Child and Adolescent $9^{\text {th }}$ Ed. Missouri: Mosby Elsevier.
2011; 177, 185, 475 pp.

3. Marshall, Jennifer. Caries-risk - Barbara Sheller and Lloyd Manci. 2010.

4. Bhalla J. Autism and Dental Management. Ontario Dentist. 2006. 27-29 pp.

5. Suryana A. Terapi Autisme, Anak Berbakat dan Anak Hiperaktif. Jakarta: Progres. 2004;9-11, 15-18, 26-27, 43-47, 77 pp.

6. Selwitz RH1, Ismail Al, Pitts NB. Dental caries. Lancet. 2007 Jan 6;369(9555):51-9. DOI: 10.1016/S0140-6736(07)60031-2

7. Danudiningrat CP. Kista Odontogen dan Nonodontogen. Surabaya: Airlangga University Press. 2006. 36 pp.

8. Mihailova, Hr., Nikolov, Vl., Slavkov, Sv. Diagnotic imaging of dentigerous cysts of the Mandible. Journal of IMAB - Annual Procceding (Scientific Papers). 2008.

9. Suwelo, I.S. 1992. Karies Gigi Pada Anak Dengan Pelbagai Faktor Etiologi.

10. Finn, S.B. 2003. Clinical Pedodontics. 4 th ed. Philadelphia : W.B. Saunders Company. 454, 477-479 pp. 